\title{
An investigation into the employment and occupation of patients with a spinal cord injury
}

\author{
R Castle DipCOT \\ Duke of Cornwall Spinal Treatment Centre. Odstock Hospital, Salisbury SP2 8BJ UK.
}

This study has attempted to ascertain the employment status of a group of 114 expatients with a traumatic spinal cord injury (SCI). The group was 1-7 years post injury. Out of the 114 subjects, $31 \%$ were in paid employment and $21 \%$ were either in full time education or training. There were $23 \%$ unemployed and seeking work and $25 \%$ unemployed and not seeking work.

Occupations prior to the spinal cord injury were wide ranging throughout all employment categories, with the engineering and science category being most prevalent. Those in employment post injury showed a move towards the administration, clerical and finance categories, with science and engineering also providing some jobs.

Keywords: spinal cord injury; employment; occupation.

\section{Introduction}

Successful rehabilitation of people with SCI is sometimes equated with a return to paid employment. ${ }^{1}$ However, individuals well adjusted to their disability and living in the community may have a lifestyle where they actively participate in the life of their family, friends and the local community without necessarily being in paid employment, and this may also be the mark of successful rehabilitation. Previous studies carried out in the United States of America have positively correlated the employed, productive person with high survival rates among persons with SCI. . $^{2,3,4}$

This study sought to find out the factors involved in returning to work and occupation levels after a major disabling injury. The following factors have been identified by previous studies: younger people are more likely to return to work than older people; paraplegics are more likely to return to work than tetraplegics; and those with a high level of education are more likely to return to work than those with a low level of education. . $^{5,7}$

\section{Methods}

The criteria for the study were as follows: patients admitted with an acute traumatic spinal injury to the Duke of Cornwall Spinal Treatment Centre, Odstock Hospital, Salisbury, from the opening of the unit in January 1984 until December 1989. Their ages ranged from over 16 years old on admission to under 60 years old on discharge. The study excluded 31 patients with incomplete spinal cord lesions who had recovered sufficiently to be discharged within 3 months of injury, returning to their former occupations. There were 214 expatients who met the criteria and formed the survey group.

The information was gathered by means of a questionnaire sent out to 214 expatients (survey group). The response rate was $53.3 \%(n=114)$.

The questionnaire was divided into five sections: personal information, details of present work/training/voluntary work, contacts with the employment services, work orientated rehabilitation while in hospital and interests/hobbies and equipment essential to maintain lifestyle.

The composition of respondents with respect to age, sex, and level and type of lesion was compared to that of the survey group. Three levels of chronological age were selected at 15 year intervals, namely 16-30, 31-45 and 46-60. Subjects were grouped according to their age on discharge 
from hospital. The subjects were categorised according to the level and nature of the lesion, as the severity of the lesion inevitably affects the lifestyle of the individual. Those termed high tetraplegia, tetraplegia and paraplegia were classed as those with a complete motor lesion. High tetraplegia was defined as $\mathrm{C} 5$ and above, tetraplegia as C5-6 to C8, paraplegia as T1 and lesions below this level, and incomplete as incomplete lesions.

For the purpose of this study occupations were grouped using the Careers Library Classification Index: ${ }^{8}$ administration/ clerical/finance; service industries/buying/ selling; science/engineering; agriculture/ environment/construction; armed services/ security/transport. This index is used by the Department of Employment.

The level of education was measured by the highest qualification gained by each subject pre injury, namely: (a) no qualifications; (b) Certificate of Secondary Education (CSE); (c) General Certificate of Education 'O' level (GCE 'O' level); (d) vocational qualifications; (e) General Certificate of Education ' $A$ ' Level (GCE 'A' level), Business and Technician Education Council (BTEC), and Ordinary National Diploma (OND); and (f) Higher National Diploma (HND), degree and postgraduate.

\section{Results}

The composition of the respondents was male $82 \%(n=94)$, female $18 \%(n=20)$. This compares with the survey group male $85 \% \quad(n=181)$, female $15 \% \quad(n=33)$. There was a slightly higher proportion of female to male among the respondents.

The respondents fell into the following age groups $16-30$ years $67 \% \quad(n=76)$, $31-45$ years $19 \%(n=22)$ and $46-6014 \%$ $(n=16)$. This compares with the survey group $16-30$ years $68 \%(n=146), 31-45$ years $20 \% \quad(n=43)$ and $46-60 \quad 12 \%$ $(n=25)$. The composition of the respondent group was slightly older than that of the survey group.

Grouped according to lesion level and type of lesion the respondents were composed of the following groups: high tetraplegia $10 \%(n=11)$, tetraplegia $16 \%(n=19)$, paraplegia $45 \% \quad(n=51)$ and incomplete lesions $29 \%(n=33)$. This compares with the survey group's composition, high tetraplegia $13 \% \quad(n=28)$, tetraplegia $16 \%$ $(n=36)$, paraplegia $45 \%(n=97)$ and incomplete lesions $25 \% \quad(n=53)$. The respondent group had a lower response rate than those with high tetraplegia and a higher response rate than those with incomplete lesions.

The figures on employment and main occupation pre injury and post injury (Table I), show an increase post injury in the unemployed, homemakers, those in full time education, training, voluntary work and the administration/clerical/finance categories, and a decrease in the other categories. In the science/engineering category, four subjects returned to their previous employment and three others found new jobs in this category. In the administration/ clerical/finance category only eight subjects returned to their previous employment with 15 others finding new jobs in this category. In the buying and selling category two returned to previous employment and only one person found a new job. In the agriculture/environment/construction and armed service/security/transport categories, only

Table I Employment or occupation pre and post injury

\begin{tabular}{lcc}
\hline & $\begin{array}{c}\text { Pre } \\
\text { injury } \\
\text { no. }\end{array}$ & $\begin{array}{c}\text { Post } \\
\text { injury } \\
\text { no. }\end{array}$ \\
\hline $\begin{array}{l}\text { Unemployed } \\
\text { Returned to work }\end{array}$ & 1 & 31 \\
$\quad$ now unemployed & & 4 \\
Homemaker & 3 & 5 \\
Voluntary work & - & 13 \\
Full time education & 9 & 11 \\
Training & - & 15 \\
Administration/clerical/ & 18 & 23 \\
$\quad$ finance & 16 & 3 \\
Services/buying selling & 28 & 7 \\
Science/engineering & 1 & 1 \\
Agriculture/environment/ & 21 & 1 \\
$\quad$ construction & 18 & 114 \\
$\quad$ Armed services/security/ & & \\
$\quad$ transport & 114 & \\
\hline Total &
\end{tabular}


two subjects returned to their previous employment, both of them having incomplete lesions with good recovery. There were no new jobs in these categories.

Overall, 16 subjects returned to their previous employment with 19 finding new jobs. Out of the subjects with new jobs, seven required periods of further training before entering paid employment. Those returning to previous employment did so within 6 months of discharge from hospital. Those embarking on new careers did so, on average, 20 months after discharge from hospital.

It should be noted that the subjects giving their occupation as 'not any' do have other interests and hobbies, which they noted in a later section of the questionnaire.

Among the female subjects $30 \%(n=6)$ were in paid employment and among male subjects $31 \%(n=29)$ were in paid employment. Out of the 20 female subjects five described their occupation as homemaker.

Employment rates in the age groups were as follows: in the 16-30 age group 37\% $(n=28)$, in the $31-45$ age group $18 \%$ $(n=4)$ and the 46-60 age group 19\% $(n=3)$. Those subjects with paraplegia and incomplete lesions had higher employment rates post injury than the two groups with tetraplegia (Table II). The group with incomplete lesions had the highest rate of employment $(39 \%)(n=13)$, followed by the group with paraplegia $(33 \%)(n=17)$.

Post injury, it was found that $(67 \%)$ $(n=6)$ of those with a HND/degree/postgraduate qualification had the highest level of employment; $50 \% \quad(n=16)$ of those subjects with CSE qualifications were in

Table II Employment rates as related to the level and type of SCI

\begin{tabular}{lcc}
\hline & $\begin{array}{c}\text { No. of } \\
\text { subjects }\end{array}$ & $\begin{array}{c}\% \text { in } \\
\text { employment } \\
\text { post injury }\end{array}$ \\
\hline High tetraplegia & 1 & 9 \\
Tetraplegia & 4 & 21 \\
Paraplegia & 17 & 33 \\
Incomplete & 13 & 39 \\
Total in employment & 35 & 31 \\
\hline
\end{tabular}

employment and those with levels of attainment in between had lower rates of employment (Table III).

All subjects were asked an open question: 'What are the main problems when considering work after injury?' Their answers were divided into those problems perceived by the employed and the unemployed. The answers were grouped as to the level and type of SCI. The frequency of a problem was noted and the lists have been prepared in order of importance (Table IV).

The services provided for the subjects by the employment service were: training twelve, special equipment nine, adaptation to premises eight, work assessment five, travel to work grant four, job introduction scheme one and sheltered placement scheme two. Training, special equipment and the adaptation of premises were the most common provisions.

Subjects were asked to consider the importance of equipment in their everyday lifestyle. They rated the equipment on a five point scale from 'essential' to 'not used'.

The groups with high tetraplegia/tetraplegia agreed that the wheelchair and telephone were essential. A car was the next most important piece of equipment. The group with high tetraplegia had television fourth on the priority list. While television ownership was universal in these two groups, a computer was owned by $60 \%$. However $90 \%$ of computer owners said that this equipment was essential or very important to them in their everyday life. The

Table III Level of education pre injury and employment post injury

\begin{tabular}{lcc}
\hline $\begin{array}{l}\text { Level of education } \\
\text { pre injury }\end{array}$ & $\begin{array}{c}\text { No. of } \\
\text { Subjects }\end{array}$ & $\begin{array}{c}\% \text { in } \\
\text { employment } \\
\text { post injury }\end{array}$ \\
\hline No qualifications & 13 & 7 \\
CSE & 16 & 50 \\
GCE O Level & 34 & 31 \\
Vocational & 16 & 37 \\
GCE A Level/BTEC/ & 17 & 7 \\
$\quad$ OND & & 67 \\
HND/degree/postgraduate & 8 & 0 \\
Did not answer & 10 & \\
Total & 114 & \\
\hline
\end{tabular}


Table IV Problems when considering work after SCI

\begin{tabular}{lll}
\hline Lesion level & Employed & Unemployed \\
High Tetraplegia & & $\begin{array}{l}\text { Access to buildings } \\
\text { Punctuality (relying on others) } \\
\text { Transport } \\
\text { Personal help-meals, lavatory etc } \\
\text { Financial (loss of benefits) }\end{array}$ \\
Tetraplegia & Access to buildings & Access to buildings \\
& Access to equipment & Lack of skills \\
& Lack of stamina & Need to retrain \\
& Convincing employers that & Punctuality (relying on others) \\
yaraplegia & Loss of benefits job & Loss of benefits \\
& Access to buildings & Access to buildings \\
Access to toilet & Loss of benefits \\
& Parking nearby & Time off sick \\
Lack of stamina & Finding new career \\
Incomplete & Low morale & Pain \\
& Access to buildings & Physical limitations \\
& Lack of stamina & Loss of benefits \\
& Physical limitations & \\
\hline
\end{tabular}

group with paraplegia had the wheelchair as the most essential piece of equipment, closely followed by a car. They listed the telephone third in priority and several subjects said that a car phone was essential. The group with incomplete lesions rated the car as top priority, with the telephone as second.

\section{Discussion}

This study was carried out during 1991 at a time of recession in the UK. The employment rate of the subjects should be viewed against the background of increasing rates of unemployment and a decrease in employment opportunities. The Duke of Cornwall Spinal Treatment Centre has a regional catchment area covering the south west of England. The figures from the Central Statistics Office for the south west region for 1991 showed an unemployment rate at 7\% of the total civilian workforce. ${ }^{9}$ The rate of paid employment among the subjects in this study was 31\% post injury. Although $69 \%$ of respondents are not in paid employment, only $23 \%$ consider themselves unemployed and seeking work.
It is also necessary to consider the definition of employment: in this study it was considered as 'paid employment'. However if employment (productive person) included not only those in paid employment but also homemakers, those in education, training and voluntary work then the employment rate would be $69 \%$.

At the time of the study the Duke of Cornwall Spinal Treatment Centre had been open for only 7 years and past studies have shown that employment rates are greater with an increase in the time since the SCI. ${ }^{10}$ It has also been reported that the adjustment process of SCI patients takes place over a period of 2 or 3 years. ${ }^{11.12}$

In the paid employment category it is interesting to note that more people started new jobs than returned to their former occupations. Those returning to previous occupations did so in the first 6 months after discharge from hospital; therefore after this period of time it is less likely that individuals will return to their former occupations. A change of career needs more time for adjustment and in some cases retraining. Those entering new jobs took, on average, 20 months after discharge from hospital. 
The female subjects had a similar rate of paid employment $(30 \%)$ to that of the male subjects $(31 \%)$. All those females in paid employment were in the paraplegic and incomplete lesion groups. However these figures were based on only 20 female respondents. It is interesting to note that five of the female subjects described their occupation as homemaker. This is a role that they acknowledge while not one male acknowledged the role of homemaker.

Past studies have shown that subjects who are younger, have paraplegia or a higher level of education are more likely to return to employment than subjects who are older, have tetraplegia and a lower education level. ${ }^{5,6,7}$ The results, based on $53 \%$ of the survey group, do support this pattern. Those subjects in the 16-30 age group had the highest employment rate at $37 \%$, this age group being the largest among SCIs admitted to the unit.

Those subjects with paraplegia and incomplete lesions had higher employment rates post injury than the two groups with tetraplegia. The subject with high tetraplegia was working in buying and selling. However all other tetraplegic subjects found new jobs in the administration/clerical/ finance category, after retraining. All tetraplegic subjects in paid employment were male. Those in the paraplegic group had more work categories open to them but did not return to work in the agriculture/ environment/construction and armed service/security/transport categories. Those with incomplete lesions took jobs in all categories.

This study shows that those with a degree had the highest level of employment (67\%) although those with CSE had a $50 \%$ level of employment. The numbers were small and could therefore not be conclusive. However half of the subjects with CSE education level did undertake further training before entering paid employment. It has been acknowledged that education post injury can be more significant as a predictor of subsequent employment than education pre injury. ${ }^{13}$ This may account, in some part, for the results.

The main problem when considering work was seen as being access to the workplace. However, those subjects in contact with the employment service received grants and advice for the adaptation of the workplace. Those employed post injury all mentioned lack of stamina and lack of confidence as being a particular problem. The unemployed, post injury, focused on loss of benefits, lack of skills, the need to have time off for sickness and physical limitations. The subjects with tetraplegia felt that they had to rely on other people for punctuality and personal care. This suggests that some of the unemployed may feel they are not in control, have poor self esteem and have lost confidence in their ability to provide for their families.

This study has shown that the SCI patient is most likely to begin a new career. This has financial implications if a new career means starting again in a junior position. Individuals need to earn enough money to offset the loss of benefits and support their families. Respondents said that it was difficult to assess the financial position of being employed against that of remaining unemployed, and this doubt and uncertainty served to fuel further loss of confidence.

The survey indicated that the SCI subjects were engaged in a wide range of activities, besides paid employment, including education, training and voluntary work. They also had hobbies and interests ranging from raising carnivorous plants and learning languages to bulldog breeding and driving a horse and cart.

The equipment which did most to improve lifestyle was noticeably that which the individuals could control for themselves. Therefore for the group with tetraplegia it was a wheelchair and a telephone, for those with paraplegia it was a wheelchair and a car, for those with an incomplete lesion a car. These pieces of equipment are linked with mobility, communication and sociability.

These findings can be compared to a study carried out in Sweden, ${ }^{14}$ where $80 \%$ of SCI subjects were engaged in gainful employment or education, and many positive factors encouraged the return to work of disabled people. In Sweden, it is a national policy to make the environment, transport and employment accessible for disabled 
people. People are encouraged to drive their own cars if possible, as it is found that mobility and social activity is associated with well being and a perceived good quality of life.

This contrasts with a study in Japan ${ }^{15}$ which showed a lower rate of employment and an environment, both public and private, which makes access for wheelchair users difficult and social isolation more likely.

The UK has a range of services designed to help the disabled person re-enter the work force. Some subjects have achieved this goal, returning to previous employment or retraining for a new career; $23 \%$ of subjects would like to find employment and the remaining $46 \%$ of subjects do not see paid employment as an option they want to pursue.

There is a need to raise awareness, among employers, the public and disabled people alike, of the services available to the disabled. It is important to enable each individual to determine his own goals and participate fully in the life of his family and community.

\section{References}

1 Neff W (1971) Rehabilitation and work. In Neff W, editor. Rehabilitation Psychology. American Psychological Association, Washington DC: 109-142.

2 Krause JS, Crewe NM (1987) Prediction of long term survival among persons with spinal cord injury: an 11 year prospective study. Rehabil Psychol 32: 205-213.

3 Kemp BJ, Vash CT (1971) Productivity after injury in a sample of spinal cord injured persons: a pilot study. J Chron Dis 24: 259-275.

4 Krause JS (1990) The relationship of productivity to adjustment following spinal cord injury. Rehabil Coun Bull 33: 188-189.

5 El Ghahit AZ. Hanson RW (1978) Variables associated with obtaining and sustaining employment among spinal cord injured males: follow up of 760 veterans. J Chron Dis 31: 363-369.

6 Geisler WO, Jousse AT, Wynne-Jones M (1966) Vocational re-establishment of patients with spinal cord injury. Med Serv J Can 22: 698-709.

7 Felton JS, Litman M (1965) Study of employment of 222 men with spinal cord injury. Arch Phys Med Rehabil 46: 809-814.

8 Careers Library Classification Index, Careers Advice and Information Centre, Sheffield.

9 Central Statistical Office (1992) Regional Trends. HMSO, London: 27.

10 Krause JS (1992) Employment after spinal cord injury. Arch Phys Med Rehabil 73: 163-169.

11 Levenson B, Green J (1965) Return to work after severe disability. J Chronic Dis 18: 167-180.

12 Stover SL, Fine PR, McEachran AB (1980) University of Alabama, Birmingham. Spinal cord injury system annual report number eight. UAB-SCI System, Birmingham: 119-129.

13 El Ghahit AZ, Hanson RW (1979) Educational and training levels and employment of the spinal cord injured patient. Arch Phys Med Rehabil 60: 405-406.

14 Siosteen A, Lundqvist C, Blomstrand C, Sullivan L, Sullivan M (1990) The quality of life of three functional spinal cord injury subgroups in a Swedish community. Paraplegia 28: 476-488.

15 Nakajima A. Honda S (1988) Physical and social condition of rehabilitated spinal cord injury patients in Japan: a long-term review. Paraplegia 26: 165-176. 